\title{
Discrete or indiscrete? Redefining the colour polymorphism of the land snail Cepaea nemoralis
}

\author{
Angus Davison $\mathbb{D}^{1} \cdot$ Hannah J. Jackson ${ }^{1} \cdot$ Ellis W. Murphy ${ }^{1} \cdot$ Tom Reader $^{1}$
}

Received: 19 September 2018 / Revised: 8 January 2019 / Accepted: 13 January 2019 / Published online: 26 February 2019

(c) The Author(s) 2019. This article is published with open access

\begin{abstract}
Biologists have long tried to describe and name the different phenotypes that make up the shell polymorphism of the land snail Cepaea nemoralis. Traditionally, the view is that the ground colour of the shell is one of a few major colour classes, either yellow, pink or brown, but in practise it is frequently difficult to distinguish the colours, and define different shades of the same colour. To understand whether colour variation is in reality continuous, and to investigate how the variation may be perceived by an avian predator, we applied psychophysical models of colour vision to shell reflectance measures. We found that both achromatic and chromatic variation are indiscrete in Cepaea nemoralis, being continuously distributed over many perceptual units. Nonetheless, clustering analysis based on the density of the distribution did reveal three groups, roughly corresponding to human-perceived yellow, pink and brown shells. We also found large-scale geographic variation in the frequency of these groups across Europe, and some covariance between shell colour and banding patterns. Although further studies are necessary, the observation of continuous variation in colour is intriguing because the traditional theory is that the underlying supergene that determines colour has evolved to prevent phenotypes from "dissolving" into continuous trait distributions. The findings thus have significance for understanding the Cepaea polymorphism, and the nature of the selection that acts upon it, as well as more generally highlighting the need to measure colour objectively in other systems.
\end{abstract}

\section{Introduction}

Throughout the past century, the study of animal colour has been critical in understanding the principles of biology, especially with respect to genetics and evolution (Cuthill et al. 2017; McKinnon and Pierotti 2010; McLean and Stuart-Fox 2014; San-Jose and Roulin 2017). For instance, early studies on the inheritance of colour traits were important in establishing an understanding of basic Mendelian genetics (Staples-Browne 1908; Wheldale 1907). Subsequently, studies on the distribution and predation of colour morphs have shaped our understanding of how natural and sexual selection operate in wild populations (Dale et al. 2015; Delhey et al. 2017;

Supplementary information The online version of this article (https:// doi.org/10.1038/s41437-019-0189-z) contains supplementary material, which is available to authorized users.

Angus Davison

angus.davison@nottingham.ac.uk

1 School of Life Sciences, University of Nottingham, Nottingham NG7 2RD, UK
Hugall and Stuart-Fox 2012). Most recently, candidate gene and latterly genomic approaches have been used to identify the underlying genes that determine the colour differences (references in Hoekstra 2006; McLean and Stuart-Fox 2014; San-Jose and Roulin 2017).

Historically, some of the most important animals in studying colour polymorphism have been the grove snail Cepaea nemoralis and its sister taxon, $C$. hortensis, because individuals are relatively easy to collect and study, and the colour morphs show straightforward inheritance. In Cepaea, we now have some understanding of the pigments and shell proteome (Mann and Jackson 2014; Williams 2017), and have begun to use new genomic methods to identify the genes involved (Kerkvliet et al. 2017; Richards et al. 2013). However, while ongoing studies on these animals continue to provide evidence for the relative role of various forms of natural selection and random drift in promoting and maintaining variation (Cameron and Cook 2012; Cameron et al. 2013; Cook 2014; Cook et al. 1999; Davison and Clarke 2000; Ożgo et al. 2017; Ożgo and Schilthuizen 2012; Schilthuizen 2013; Silvertown et al. 2011), progress in understanding the patterns of shell variation in Cepaea has largely stalled since the 1970s. 
In part, this may be a reaction to (Jones et al. 1977) questioning whether the Cepaea polymorphism is "a problem with too many solutions?" Actually, the intention of that work was to emphasise the perfect case study provided by Cepaea. As simple explanations for phenotypic variation are the exception, they were making the point that it is important to study organisms for which polymorphism may be explained by a variety of processes, precisely because they are more realistic. Given that present-day genomic technologies should allow us to uncover the relative contributions of each of these processes in making contemporary diversity, this point is perhaps just as prescient now.

However, one remaining problem is that Cepaea shell colours are usually treated as one of three or more discrete classes (e.g. Cain and Sheppard 1954), yellow, pink or brown, partly because laboratory crosses have shown that colour is predominantly coded by three (or more) alleles at a single locus in the a "supergene", but also due to a lack of objective measures of colour (Cain et al. 1960; Cain et al. 1968; Jones et al. 1977). There is also the significant issue that human perception of colour is not necessarily objective or the same as that of a predator (Surmacki et al. 2013). Therefore, before we proceed further, there is a pressing need to quantify objectively the shell phenotype of Cepaea, and to understand how this is perceived by predators, whether avian, mammalian or invertebrate. Minimally, an objective measure of quantitative variation should be seen as a requirement for a formal definition of the polymorphism.

The use of quantitative analyses of pigmentation are increasingly commonplace in other systems (Corl et al. 2018; Huber et al. 2015; Jones et al. 2012; Rankin et al. 2016), including the recognition that it is important to consider crypsis from the sensory perspective of the predator (Eacock et al. 2017; Holveck et al. 2017; Pike 2018). Now that these methods are widely available and routine (Delhey et al. 2015; Endler 1990; Kemp et al. 2015; Maia et al. 2013; Maia and White 2018; Montgomerie 2006), they may be used to measure the ground colour of Cepaea shells, so as to bring the methodology used in a classic and important system up to current standards.

Previously, Surmacki et al. 2013 used quantitative measures of colour on relatively few individuals to assess how shells match to various backgrounds. In our study, we aimed to measure the shell colour of snails collected across the breadth of the European distribution, using psychophysical models of colour vision to assess how chromatic variation is perceived by birds (but not categorised; Caves et al. 2018), because of the greater literature on avian predation, and also because their visual perception is better characterised.

Specifically, we investigated the extent to which the distribution of snail shell colour is continuous along the main axes of chromatic variation, using more than a thousand individuals and Gaussian finite mixture modelling (Scrucca et al. 2016) to test whether colours fall into clusters in multivariate space. These data are compared using both avian models of vision and model-free analyses. Finally, we also aimed to understand if quantitative measures of these shells can describe - rather than explain geographic patterns in colour morph frequency across Europe, as others have done in much larger qualitative surveys (Silvertown et al. 2011).

The findings have significance for understanding the Cepaea polymorphism, and the nature of the selection that acts upon it, as well as more generally highlighting the need to measure colour objectively in other systems.

\section{Materials and methods}

\section{Data collection}

Individual $C$. nemoralis snails were mainly gathered opportunistically by volunteer-led collection and field trips across Europe (Grindon and Davison 2013; a few snails from an introduced population in Canada were also used). Snails were frozen upon arrival at the University of Nottingham, subsequently thawed and the body extracted from the shell. The ground colour and banding of the shell were then scored qualitatively by an experienced person (A.D.) and a student, as either yellow (Y), pink (P) or brown (B), and unbanded $(\mathrm{O})$, mid-banded $(\mathrm{M})$, or all other banding patterns (B, usually five-banded). Subsequent statistical analyses were carried out at the level of the individual and the level of the population (sample site). So that we could compare broad-scale patterns across Europe, larger groups were also used - individual sample sites were therefore grouped into one of six groups (Table S1; Fig. 1).

An Ocean Optics spectrometer (model USB2000+UVVIS-ES) and a light source (DT-MINI-2-GS UV-VIS-NIR) were used to measure individual reflectance spectra of shells, using a WS-1 diffuse white reflectance standard to set the baseline light spectrum (Taylor et al. 2016; Teasdale et al. 2013), and complete darkness to set the dark spectrum standard. Reflectance measurements were taken on the underside of the dried shell, because it was usually the least damaged or worn region, least exposed to sunlight, and well away from any bands.

Point samples were taken for each shell at a $45^{\circ}$ incident angle, $\sim 2 \mathrm{~mm}$ from the shell. Individual shells were measured three times, non-consecutively, with the software recalibrated against light standards every 2-5 measurements. These repeat measures were necessary to attempt to control for experimental error and minor variations in the local colour of the shell underside. 


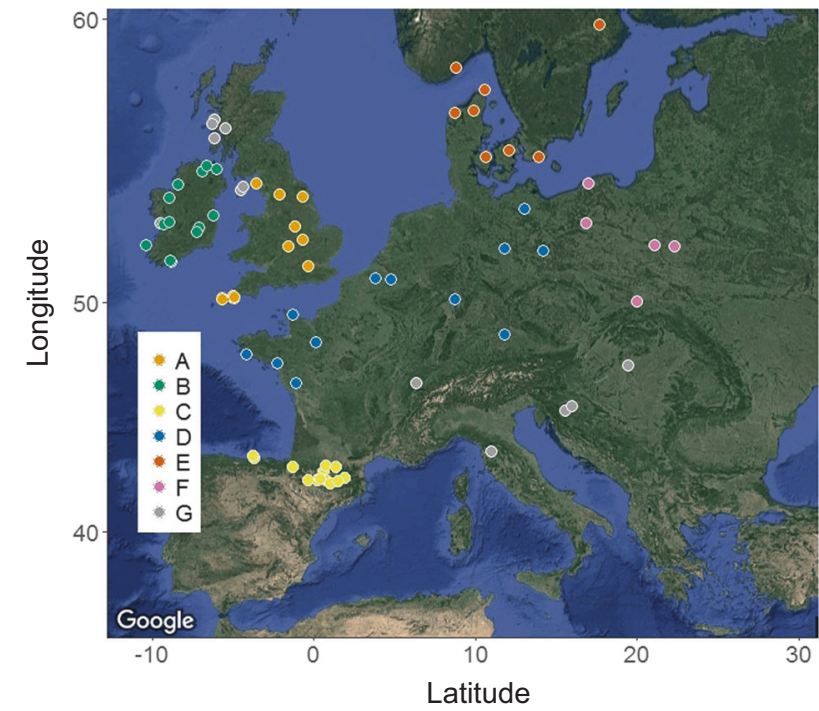

Fig. 1 Sample sites across Europe, grouped by geographically contiguous regions. a (England, $n=397$ ), b (Ireland, $n=144$ ), c (North Spain and Pyrenees, $n=112$ ), d (North France, Belgium, Germany, $n=178$ ), e (Scandinavia, $n=77)$, f (Poland, $n=126$ ). One final group, $\mathbf{g}$, is all other samples $(n=138)$

Readings were collected using Ocean Optics SpectraSuite v. 2.0.162 (software settings: integration time $750 \mathrm{msec}$, boscar width 5 , scans to average 10 ); then the raw data smoothed and binned into $5 \mathrm{~nm}$ categories using Pavo version 0.5-6 (Maia et al. 2013).

\section{Analysing chromatic and achromatic variation}

We used the framework provided by Delhey et al. 2015 to analyse the reflectance spectra. In this framework, a psychophysical model of colour vision (Vorobyev and Osorio 1998; Vorobyev et al. 1998) is used to assess whether chromatic differences between reflectance spectra exceed a discrimination threshold, or 'just noticeable difference' (JND), which can be perceived by a receiver, such as an avian predator. The key to these models lies with the degree to which a particular combination of reflectance and illuminant spectra stimulates each of the different photoreceptors in the retina. In birds, these photoreceptors are the four single cones used for colour vision, which are sensitive to long (L), medium (M), short (S), and very short (VS) wavelengths of light (Cuthill 2006).

To analyse chromatic variation, the quantum catches for each cone type were converted into three chromatic coordinates $(x, y$ and $z$ ), where Euclidean distances between points reflect perceptual differences, using the formulas of Cassey et al. 2008. As there are no data for the song thrush, Turdus philomelos, which is the main avian predator of Cepaea, we used inferences from the closest available relative, the blackbird Turdus merula (Hart 2001; Hart et al. 2000), namely the relative abundance of each photoreceptor in the retina, or cone proportions of VS: $0.528, \mathrm{~S}: 0.904, \mathrm{M}$ : 1.128, L: 1 , and sensitivity functions of $373,461,543$ and 603 , respectively. The analysis assumed that the $\mathrm{L}$ cone has a noise-to-signal ratio of 0.05 (Delhey et al. 2015), so that the ratios for the other cones were VS: 0.0688 , S: 0.0526 and M: 0.0471 . Note that there is debate on the appropriate noise-to-signal ratio for chromatic and achromatic vision, varying over a four-fold range from 0.05 to 0.1 or 0.2 (Olsson et al. 2018). If we were to use a higher ratio, then it would mean dividing all $x y z$ values by 2 or 4 , affecting the magnitude of the JNDs, but not the overall interpretation. The irradiance spectrum of "standard daylight" (d65) was used for the main analyses. However, analyses were also run for "woodland shade" to test the influence of illuminant on avian perception of colour (Vorobyev et al. 1998).

To identify the main axes of chromatic variation, we carried out a Principal Components Analysis (PCA) on the chromatic coordinates ( $x, y$ and $z$ ), preserving the perceptual distances (JNDs) by using a covariance matrix rather than a correlation matrix (Delhey et al. 2015). To understand whether there are potential clusters within the chromatic coordinate data, Gaussian mixture modelling was carried out using Mclust 5.3 in $\mathrm{R}$ version 3.3.3 (Scrucca et al. 2016). A number of models were compared, each of which assumed a different number of clusters (from 1 to 10), normally distributed in multivariate chromatic space. Several classes of model were considered, each with a different assumption about the homogeneity of variance and orientation among clusters. The best fitting model was then determined as the one with highest Bayesian Information Criteria (BIC), with significant differences determined using a bootstrap approach.

The methods of Delhey et al. 2015 were also used to assess achromatic variation, "brightness" or luminance variation. In birds, sensitivity to achromatic cues is supposed to be mediated by double cones which have the same pigment as L cones in birds but different oil droplets, so have a wider sensitivity range. Values of achromatic contrast were therefore estimated, again in JNDs, by computing achromatic contrast between each reflectance spectrum and a reference (a very low value of double cone quantum catch, 0.001), corresponding to a dark spectrum, and using the same noise-to-signal ratio.

\section{Local variation}

The main analyses, above, were used to understand how variation is partitioned across a broad geographic region. As avian predators act within a small geographic region, it is also important to understand variation at a local level. For this reason, we separately plotted chromatic variation in the two largest single samples within the dataset, Beeston $(n=$ $98)$ and Bathhill $(n=55)$. 


\section{Model-free analysis}

We were interested to compare the output from the above analyses, which assume a model of avian vision, against an assumption-free analysis of the raw data. A principal components analysis was carried out on the $5 \mathrm{~nm}$ sampled reflectance data. Gaussian mixture modelling was then carried out on the PCA values, using Mclust as previously.

\section{Analysis of morph frequencies}

We investigated evidence for effects of location and banding on the likelihood that a snail belonged to a particular colour morph, as defined by the analysis of chromatic variation, using generalised linear mixed effects models (GLMMs) with binomial errors. Each morph was considered separately, with each snail to be scored as belonging to the focal morph (1) or not (0). The three analyses are not independent, since each snail can belong to one morph only. Banding pattern was fitted as a fixed factor, whilst the effect of geographic location was examined at three spatial scales. Variation in morph frequency at a local level was modelled with random effect for site. Variation at a regional level was considered by fitting a fixed effect of geographic region. Finally, continental scale variation was modelled by looking for fixed linear and quadratic effects of latitude and longitude.

The fact that region and latitude/longitude are partially collinear was reflected in the model-fitting procedure. We first fitted a saturated model with all main effects, except for region, and their two-way interactions (excluding interactions involving quadratic effects). Then, fixed terms were removed in a stepwise fashion, testing the effect of deletion using likelihood ratio tests, until only significant terms remained. Effects of latitude/longitude were then substituted with an effect of region and we compared the Akaike Information Criterion (AIC) of the resulting models, to test whether region was better at capturing any large-scale geographic variation. Testing random effects in generalised linear mixed models is problematic, so we compared the AIC of the saturated GLMM with that of a generalised linear model without the random term for site to provide an approximate test of the importance of site (following Zuur et al. 2009).

\section{Results}

\section{Variation in colour}

We measured the individual reflectance spectra of 1172 shells, mainly collected from across Europe (Tables S1, S2; Fig. 1) and then transformed them into visual space coordinates, $x y z$. To visualise this chromatic variation, the $x y z$ coordinates were plotted in avian visual colour and colour coded according to human-scored (Supplementary Movie 1) and Mclust-defined colour categories (Fig. 2;
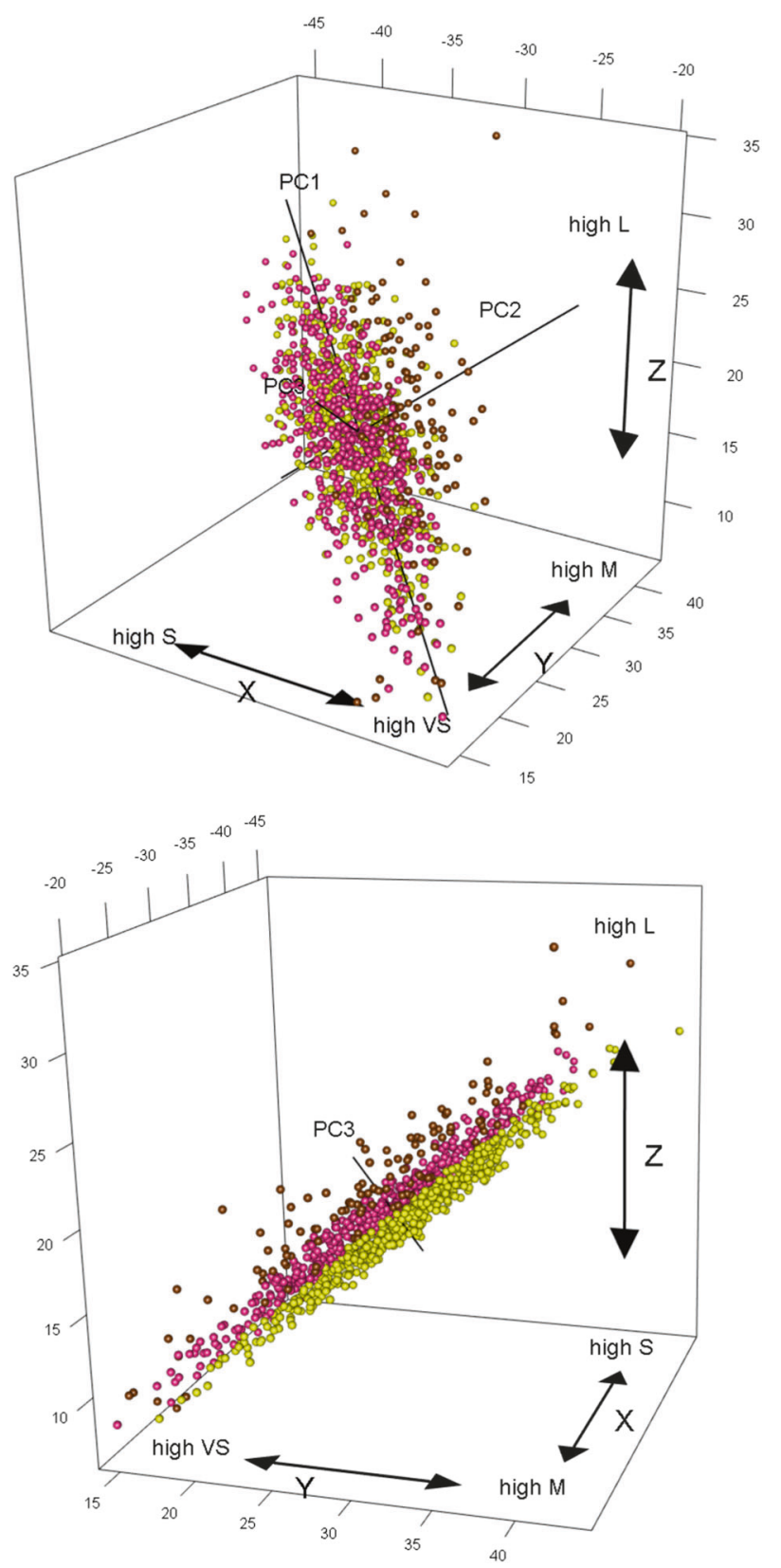

Fig. 2 Axes of chromatic variation in the shell of $C$. nemoralis, using avian visual space, shown from two different perspectives (see also Supplementary Movie 2). Units on $x, y$ and $z$ axes are in JNDs. The solid lines illustrate variation along the first three principal components; individual points are coloured according to Mclust classification of the shell, either yellow, pink or brown. Top: Variation along PC1 (87\%) mainly represents differences in saturation between shells, with some more limited variation in stimulation of L cones. PC2 $(11 \%)$ shows relatively higher stimulation of $\mathrm{L}$ cones and lesser stimulation of $\mathrm{M}$ and $\mathrm{S}$ cones, and tends to separate brown from pink/yellow. Bottom: PC3 (2\%) shows relatively high stimulation of the M cones compared to lesser stimulation of the $\mathrm{S}$ and $\mathrm{L}$ cones, and tends to separate yellow from pink and pink from brown 
Supplementary Movie 2). The range of observed variation on each axis was large at 41, 22 and 8 JNDs for $x, y$ and $z$, respectively (Fig. 2; still considerable even if a higher noise-to-signal were used, Olsson et al. 2018). There were no obviously discrete groups.

A PCA on the $x y z$ coordinates showed a first axis which explained $87 \%$ of chromatic variation. PC1 had a moderatepositive loading for $x(0.61)$, and a moderate negative loading for $y(-0.64)$ and $z(-0.46)$. Two further axes explained 11 and $2 \%$ of the variation, the second having a positive loading on all axes $(0.75,0.28,0.61$, respectively), and the third a mixture $(-0.26,-0.71,0.65)$.

Plotting the average normalized reflectance spectra for each quartile of each principal component showed how the three PC axes correspond to chromatic variation (Fig. 3). Variation along PC1 represents relatively high stimulation of $\mathrm{L}$ cones and lesser stimulation of $\mathrm{S}$ cones, relative to $\mathrm{M}$ cones. Variation in $\mathrm{PC} 2$ showed relatively higher stimulation of $\mathrm{L}$ cones and lesser stimulation of $\mathrm{M}$ cones. PC3 showed relatively high stimulation of the $\mathrm{M}$ cones compared to lesser stimulation of the $\mathrm{S}$ and $\mathrm{L}$ cones. Only PC1 showed any differences in the VS region, but the shells barely reflected in the UV $(<400 \mathrm{~nm})$.

To investigate whether snail shells cluster in chromatic space, and whether observed clusters correspond to humanscored qualitative colour morphs, Gaussian finite mixture modelling was applied to the $x y z$ visual space coordinates. The best model (VVV, ellipsoidal, varying volume, shape, and orientation; BIC $-15,727.3 ; P<0.001$ compared $2^{\text {nd }}$ best model) recovered three clusters, which happen to roughly correspond to human-scored yellow $(46 \%, n=$ $539)$, pink $(44 \%, n=511)$ and brown $(10 \%, n=122)$ (Table 1). The next best fitting model also recovered three clusters (VEV; BIC $-15,749.3 ; P<0.001$ compared with $3^{\text {rd }}$ best model) and the third recovered four clusters (EEV; BIC $-15,755.5$; the $4^{\text {th }}$ cluster contained only 16 individuals).

Comparing human-scored (A.D.) and Mclust-defined groups, the overall concordance was good at $76 \%$ (Table 1), with a similar rate $(75 \%)$ for the student group. Perhaps the main difference was that human-scoring reported relatively few brown shells $(n=37)$, whereas the same group in Mclust was larger $(n=122)$. The highest proportion of discordant scores were human-scored yellow shells that Mclust classed as pink (10\% for A.D.; 12\% for student group), with the other major discrepancies being humanpink classed as Mclust-brown (8\%), and human-yellow classed as Mclust-pink (4\%).

With misclassifications adjusted relative to the total number of each Mclust shell type, $81 \%$ of the brown group were in a different human-scored group (74\% pink, 7\% yellow), compared to $26 \%$ of the pinks (3\% brown $23 \%$ yellow) and just $8 \%$ of yellows ( $8 \%$ pink, $0 \%$ brown). Thus,
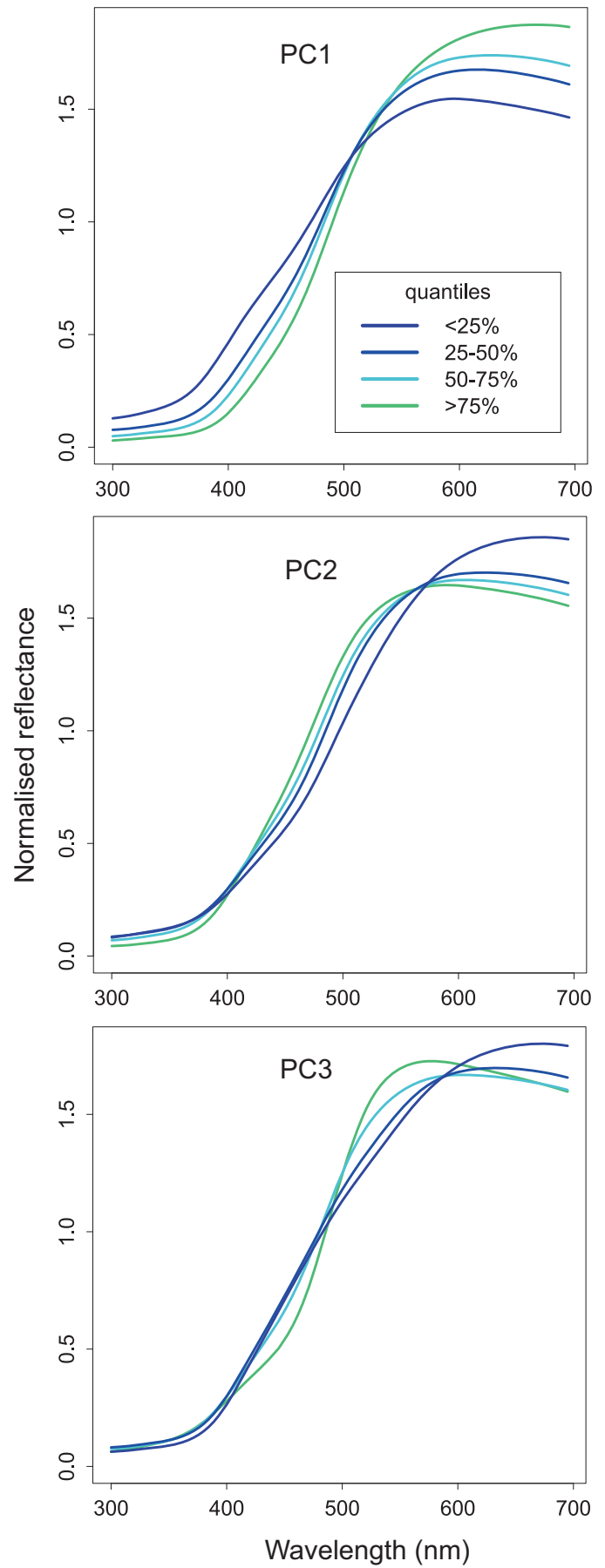

Fig. 3 Interquartile ranges of the average normalised reflectance spectra for the principal component axes shown in Fig. 2. These plots confirm that variation on $\mathrm{PC} 1$ mainly represents differences in saturation between shells; PC2 represents relatively higher stimulation of $\mathrm{L}$ cones and lesser stimulation of $\mathrm{M}$ and $\mathrm{S}$ cones; PC3 represents relatively high stimulation of the $\mathrm{M}$ cones compared to lesser stimulation of the $\mathrm{S}$ and $\mathrm{L}$ cones

while the overall correspondence between human and Mclust scoring of shell colour was good, the yellows were scored accurately (92\%), pinks less so (74\%) and brown poorly (19\%). 
Table 1 Comparison between human-perceived colour categories and Mclust-defined groups, the latter based on the output of a principal components analysis of the $x y z$ values

\begin{tabular}{lllllll}
\hline \multirow{2}{*}{$\begin{array}{l}\text { Colour } \\
\text { (Mclust) }\end{array}$} & & Yellow & Pink & Brown & Total $\begin{array}{l}\text { \% total } \\
\text { misclassified }\end{array}$ \\
\cline { 3 - 7 } & Yellow & $\mathbf{4 9 5}$ & 44 & 0 & 539 & 8.2 \\
& Pink & 118 & $\mathbf{3 7 9}$ & 14 & 511 & 25.8 \\
& Brown & 9 & 90 & $\mathbf{2 3}$ & 122 & 81.1 \\
& Total & 622 & 513 & 37 & & \\
\hline
\end{tabular}

Shells that were scored the same are on the diagonal (in bold). Yellow and pink were most common, and so the absolute number of discordant scores was relatively low. Brown had by far the highest proportion of discordant scores

Plots of human-scored colours along the three PCs (Supplementary Movie 1) and Mclust-categories were concordant with the above analyses (Figs. 2, 4; Supplementary Movie 2). Broadly, PC1 did not separate different human-perceived colours or categories of shell, but instead mainly represents differences in saturation, or purity of colour/steepness of the slope of the wavelength, between individuals, with perhaps more limited variation in long wavelengths (Fig. 4). PC2 separated brown from yellow and pink, and PC3 broadly separated all three colours, yellow, pink and brown.

The above analyses were repeated using "woodland shade" rather than standard daylight. The main difference was that while Mclust again recovered three groups, brown shells were more common $(14 \%, n=168)$, with fewer pinks $(40 \%, n=474)$ and approximately the same number of yellows $(45 \%, n=530)$.

Finally, achromatic variation was also considerable and without any obvious differences between Mclust-defined colour morphs (Supplementary Fig. 1). It is not clear how much of this variation is due to differences in the snail shell and how much is due to slight differences in illuminance and proximity of the probe.

\section{Local variation}

The colour polymorphism in the Beeston sample was straightforward to score, as either pink or yellow. These same shells showed a discrete distribution in avian visual colour space, whether plotted according to humanperception of colour (Fig. 5a, Supplementary Movie 3) or Mclust classification (Fig. 5b; Supplementary Movie 4). In comparison, the colour polymorphism in the Bathhill sample was difficult to score. When plotted in avian visual colour space, there was no evidence of a discrete boundary between human-perceived pink and yellow shells from Bathhill (Fig. 5c; Supplementary Movie 5), or Mclustclassified pink and yellows (Fig. 5c; Supplementary Movie 6). Mclust also predicted fewer brown shells.
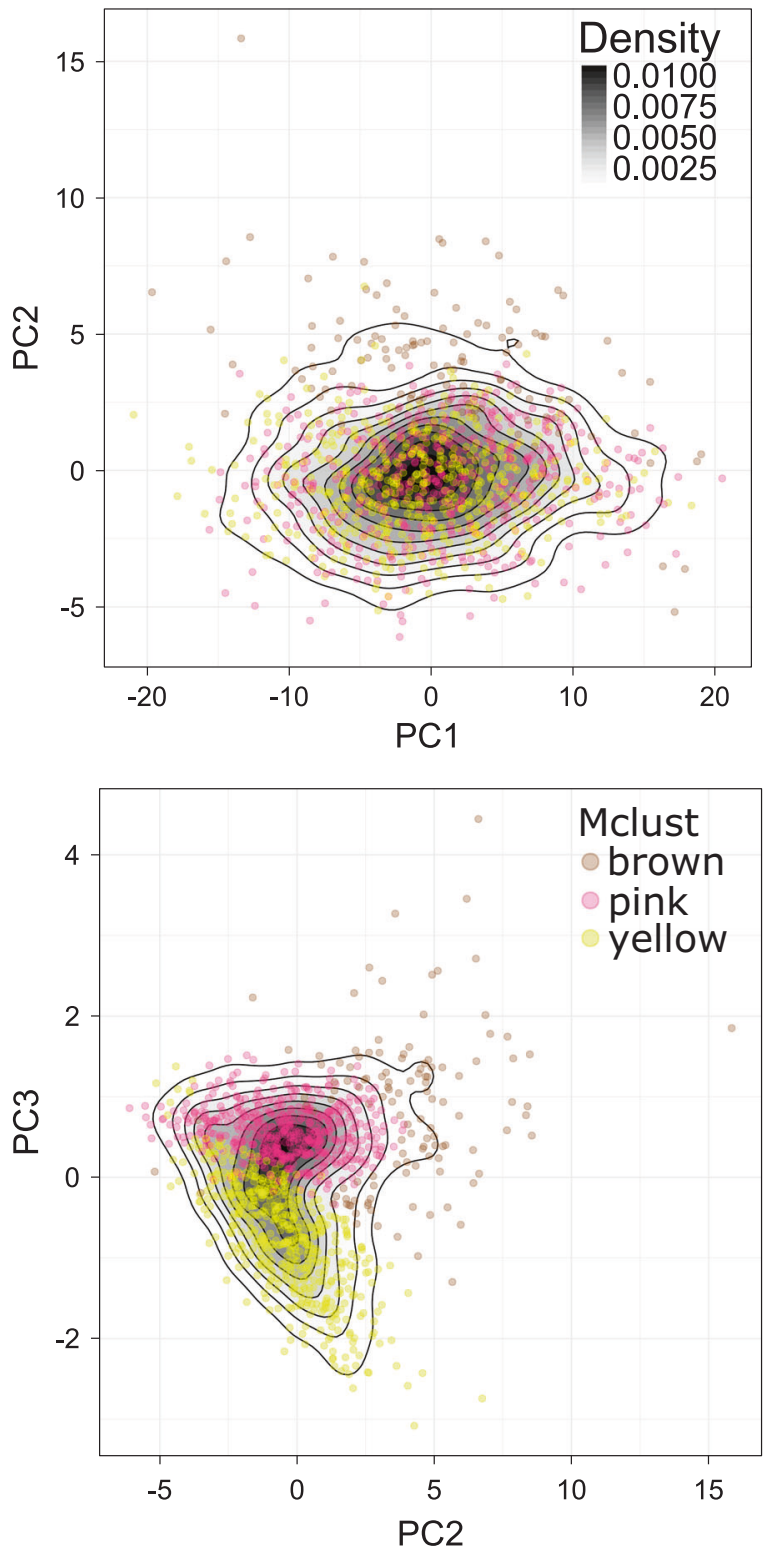

Fig. 4 Scatterplot and associated density plot, showing variation of visual space coordinates, $x y z$, on three principal component axes. Units are in JNDs; darker black indicates relatively more dense regions (see Legend). Points are coloured according to Mclust classification of the shell, either yellow, pink or brown. Top: PC1 versus PC2. Bottom: PC2 versus PC3

\section{Model-free analysis}

A PCA on the raw reflectance data (5 nm samples) showed a first axis which explained $90 \%$ of variation; two further axes explained 7 and $2 \%$ of the variation. Gaussian mixture modelling using Mclust recovered six clusters in both the first and second best models; with the third best model recovering three clusters. None of these clusters strongly correspond to human-perceived colours (Table 2), except possibly a subset of yellows and pinks on PC3 
a)

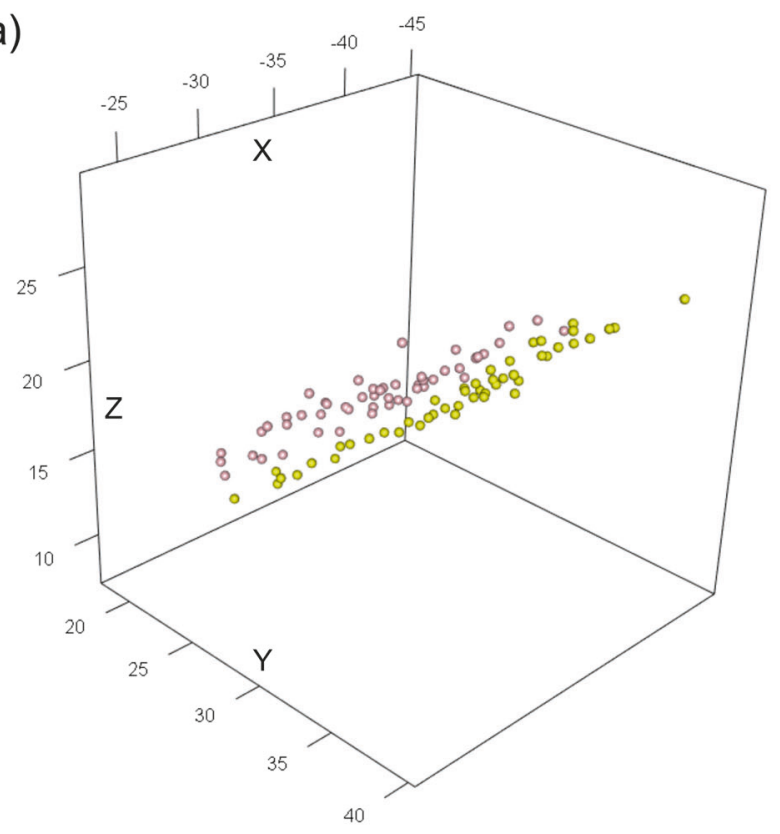

c)

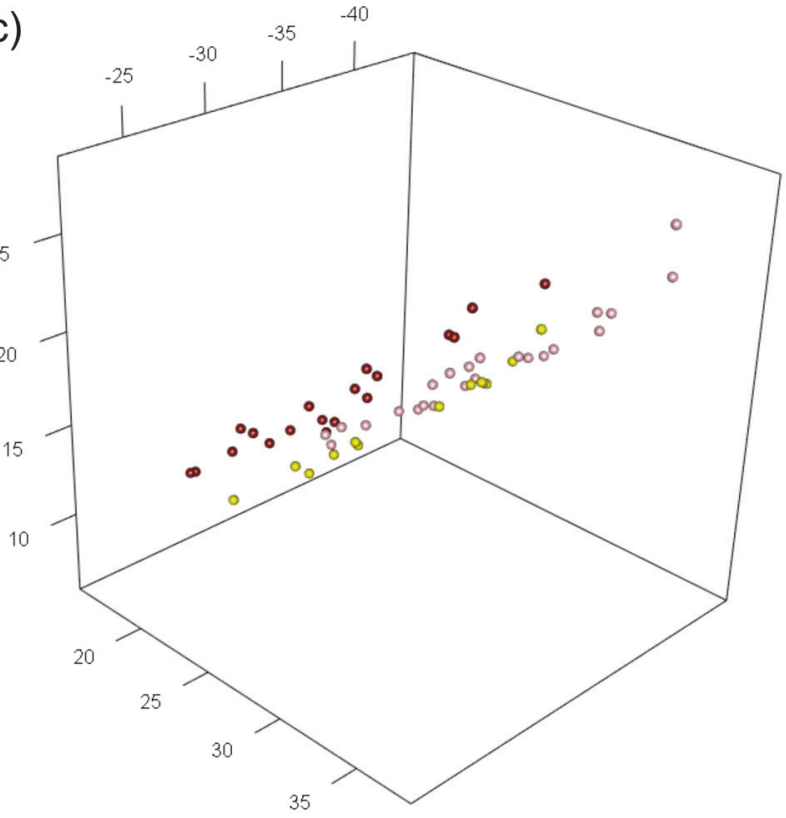

Fig. 5 Axes of chromatic variation in the shell of $C$. nemoralis, using avian visual space. Units on $x, y$ and $z$ axes are in JNDs. a and $\mathbf{b}$ represent snails from a "Beeston" population sample, with individual points coloured yellow, pink or brown according to human a or Mclust

(Supplementary Fig. 2); it is possible that the clusters correspond to pigments (Williams 2017).

\section{Geographic variation between morphs}

Large-scale geographic variables (latitude, longitude and region) had significant effects on the probability that a snail was pink or yellow, but not the probability that a snail was brown (Table 3). Pink morphs were significantly less
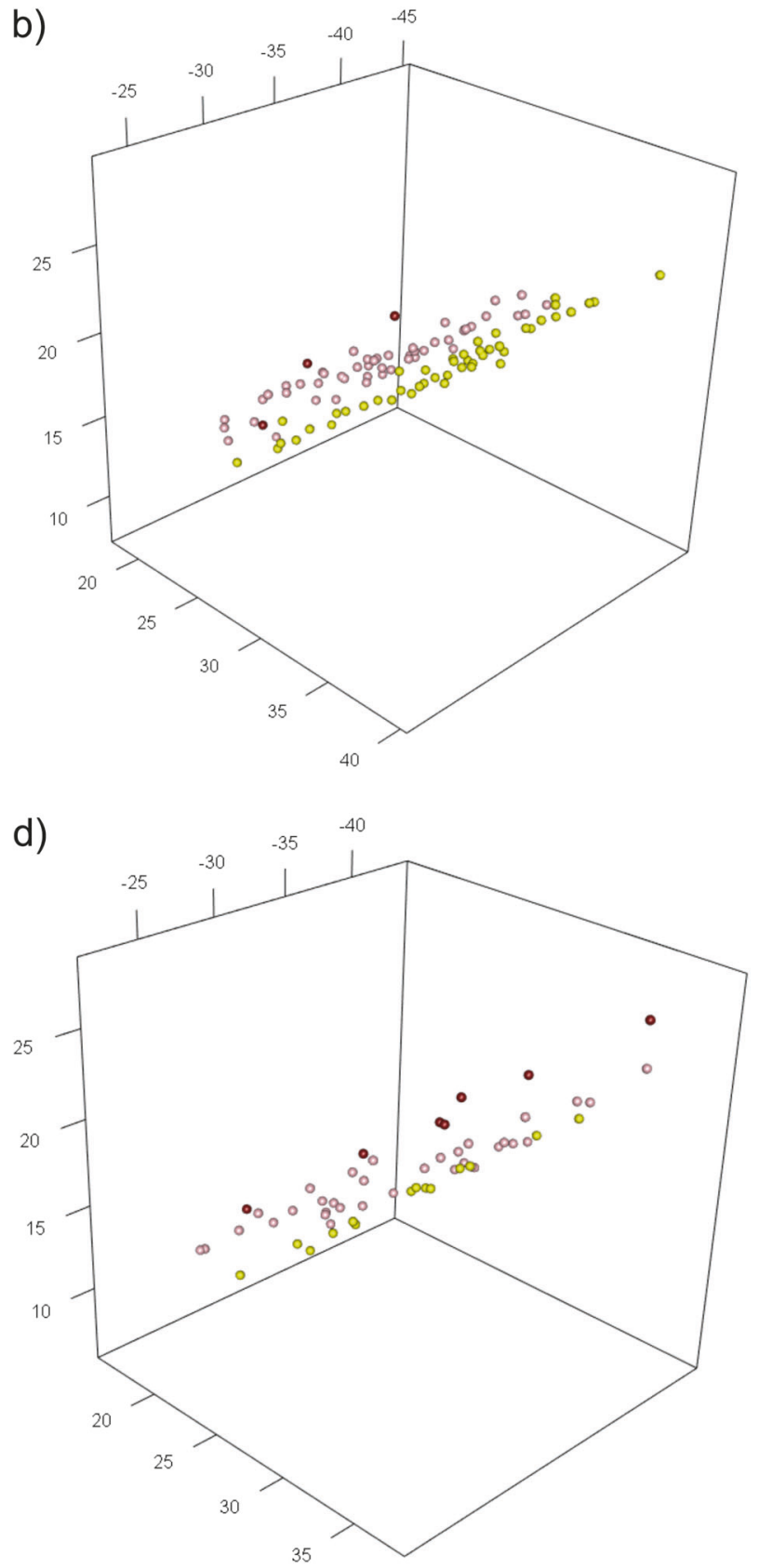

b classification of the shell. Similarly, $\mathbf{c}$ and $\mathbf{d}$ represent snails from the "Bathhill" sample, with individual points coloured to human c or Mclust d classification of the shell. See also Supplementary Movies 3 to 6

common at mid-latitudes (Fig. 6). Snails with more than one band (B) and those which were mid-banded (M) were more likely to be pink in the west, while unbanded (O) snails were more likely to be pink in the east (Fig. 6). In contrast, yellow snails were less common at high latitudes, and were affected by an interaction between longitude and banding which was the reciprocal of that seen in pink snails (Fig. 7).

Morph frequencies also varied at a local level. A saturated mixed model including the random effect of site was 
much better (Brown AIC $=443.7$; Pink AIC $=868.9$; Yellow $\mathrm{AIC}=852.8)$ than an equivalent model without the random effect (Brown $\mathrm{AIC}=646.4$; Pink $\mathrm{AIC}=1407.9$; Yellow AIC $=1416.2$ ). This means that variation among individual local populations was greater than expected, even after accounting for any larger-scale geographic variation captured by the fixed effects of latitude and longitude.

Banding was associated with colour morph in various ways. In addition to the interaction between banding and longitude in pink and yellow snails mentioned above, unbanded snails $(\mathrm{O})$ were generally more likely to be brown ( $14 \%$ of all unbanded snails), than snails that were midbanded $(\mathrm{M} ; 11.6 \%)$ or had several bands $(\mathrm{B} ; 5.8 \%)$.

\section{Discussion}

By measuring the ground colour of Cepaea nemoralis shells collected across the breadth of the European distribution,

Table 2 Comparison between Mclust-defined groups, defined by either the output of a principal components analysis of the $x y z$ values, or a model-free PCA of the wavelength data

\begin{tabular}{lllllllll}
\hline \multirow{2}{*}{ Colour $(x y z)$} & & \multicolumn{7}{c}{ Group (model-free PCA) } \\
\cline { 2 - 9 } & & 1 & 2 & 3 & 4 & 5 & 6 & Sum \\
\hline & Yellow & 14 & 124 & 1 & 66 & 1 & 333 & 539 \\
& Pink & 192 & 37 & 89 & 109 & 49 & 35 & 511 \\
& Brown & 13 & 9 & 62 & 8 & 28 & 2 & 122 \\
\hline
\end{tabular}

The six groups identified by Mclust in the model-free analysis do not simply map onto the three groups identified by Mclust from the PCA of the $x y z$ values we used psychophysical models of avian vision to understand how the shell colour may be perceived by birds, and to describe how this varies in geographic space, and with respect to other characters, such as banding. The findings have significance for understanding the Cepaea polymorphism, and the nature of the selection that acts upon it, as well as more generally highlighting the need to objectively measure colour variation in other systems.

Broadly, we found that both chromatic (Fig. 2) and achromatic variation (Supplementary Fig. 1) is considerable, occurring over many perceptual units (JNDs). If this variation, both within and among human-perceived colour morphs, affects prey detection or identification by avian predators, then the presumption is that the polymorphism must be impacted by natural selection. The current available evidence suggests that animals in general use chromatic and achromatic signals for separate tasks, for example, using achromatic signals to identify the location, shape and motion of objects, while chromatic signals identify surface quality (Osorio and Vorobyev 2005). However, while this is also likely the case for avian predators, specific experimental evidence from birds is sparse (Kang et al. 2015; Osorio et al. 1999; White and Kemp 2016).

We also found that chromatic variation in shells is continuously distributed in visual space, meaning that there are no wholly discrete colours (Fig. 2). Perhaps surprisingly, we found that the most variable chromatic axis $(\mathrm{PC} 1 ; 87 \%)$ that would be visible to a bird mainly reflects the degree of saturation, or purity of colour. Axes separating humanperceived colours showed less variation, PC2 (11\%) separating brown from yellow/pink, and PC3 (2\%) broadly separating yellow, pink and brown.
Table 3 Results of likelihood ratio tests of the terms in binomial GLMMs of the effects of geographic variables and banding phenotype on the probability that a snail belonged to each of the three colour morphs

\begin{tabular}{|c|c|c|c|c|c|c|c|c|c|}
\hline \multirow{4}{*}{$\begin{array}{l}\mathrm{AICa}(\mathrm{df}) \\
\mathrm{AICb}(\mathrm{df}) \\
\text { Term }\end{array}$} & \multicolumn{3}{|c|}{ Brown } & \multirow{2}{*}{\multicolumn{3}{|c|}{$\frac{\text { Pink }}{865.2(11)}$}} & \multicolumn{3}{|c|}{ Yellow } \\
\hline & \multirow[b]{3}{*}{ df } & \multirow[b]{3}{*}{$\chi^{2}$} & \multirow[b]{3}{*}{$p$-value } & & & & \multicolumn{3}{|c|}{$850.2(8)$} \\
\hline & & & & \multicolumn{3}{|c|}{875.4 (22) } & \multicolumn{3}{|c|}{872.09 (22) } \\
\hline & & & & $\mathrm{df}$ & $\chi^{2}$ & $p$-value & $\mathrm{df}$ & $x^{2}$ & $p$-value \\
\hline Latitude & 1 & 1.747 & 0.186 & 1 & 0.218 & 0.641 & 1 & 2.62 & 0.106 \\
\hline Longitude & 1 & 1.572 & 0.21 & 1 & 1.382 & 0.24 & 1 & 0.001 & 0.986 \\
\hline Latitude $^{2}$ & 1 & 2.019 & 0.155 & 1 & 1.832 & $<0.001$ & 1 & 4.732 & 0.03 \\
\hline Longitude $^{2}$ & 1 & 2.587 & 0.108 & 1 & 0.214 & 0.644 & 1 & 0.355 & 0.551 \\
\hline Banding & 2 & 10.751 & 0.005 & 2 & 0.286 & 0.867 & 2 & 3.056 & 0.217 \\
\hline Latitude $\times$ longitude & 1 & 0.239 & 0.625 & 1 & 0.0877 & 0.767 & 1 & 0.023 & 0.88 \\
\hline Latitude $\times$ banding & 2 & 1.411 & 0.494 & 2 & 6.345 & 0.042 & 2 & 4.972 & 0.083 \\
\hline Longitude $\times$ banding & 2 & 4.255 & 0.119 & 2 & 12.935 & 0.002 & 2 & 27.043 & $<0.001$ \\
\hline Region & 6 & 10.586 & 0.102 & 6 & 7.481 & 0.279 & 6 & 5.924 & 0.432 \\
\hline Banding $\times$ region & 12 & 12.824 & 0.382 & 12 & 34.564 & 0.001 & 12 & 31.448 & 0.002 \\
\hline
\end{tabular}

Significant $p$-values are in bold. The effects of modelling large-scale geographic variation in two ways are illustrated by the AIC values for the best model in which linear and quadratic effects of latitude and longitude were included (AICa), and the best model in which geographic region was included (AICb). All models include a random effect for site 

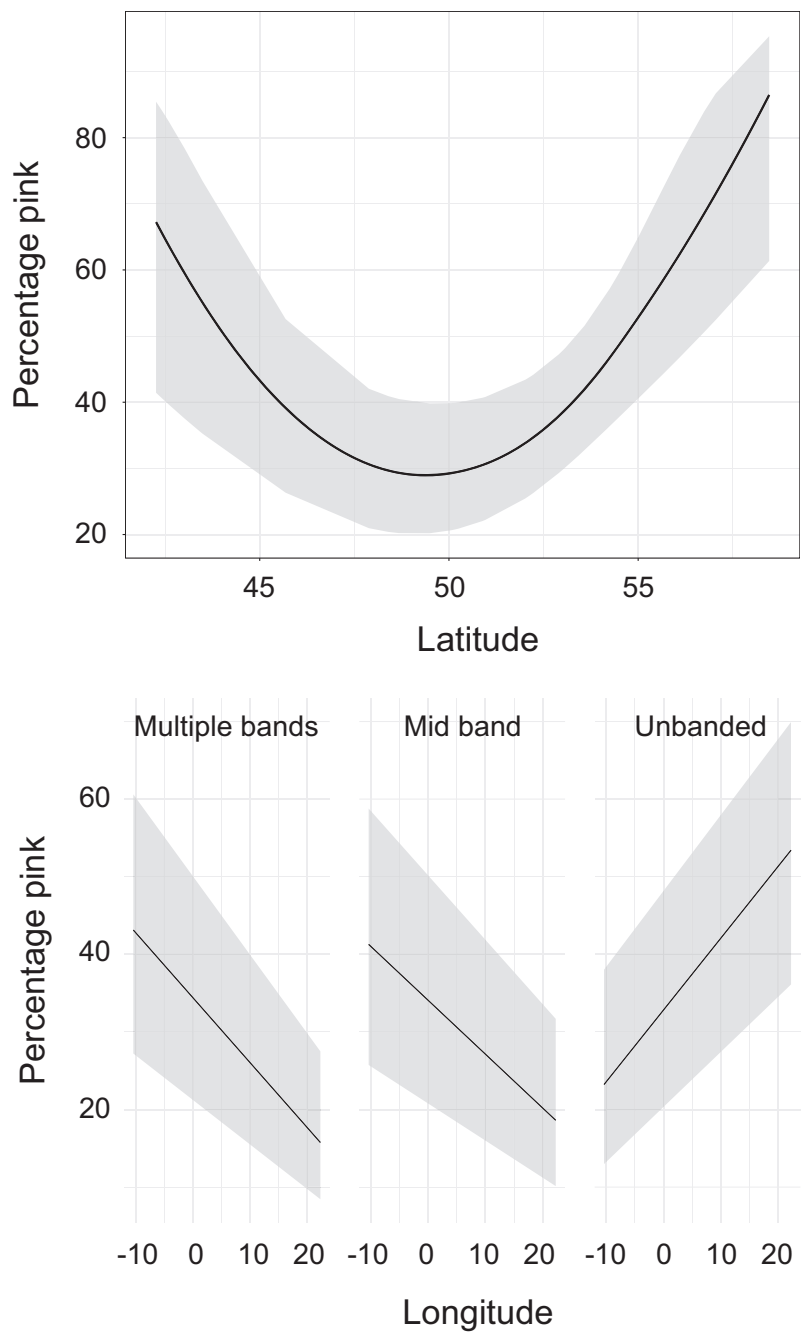

Fig. 6 Scaled effects of latitude on the proportion of pink shells (top), and longitude on banding and proportion of pink shells, showing $95 \%$ confidence limits

Despite the lack of discrete colours, density-based clustering recovered three main shell types, which roughly correspond to human-perceived yellow, pink and brown (Table 1; Figs. 3, 4; model-free analyses produced more clusters, which only partly correspond to human-perceived colours, Supplementary Fig. 2). Brown shells were more common according to the objective analysis than are perceived by humans, with the frequency higher again when using "woodland shade" as an illuminant. Therefore, prior studies that (necessarily) used changes in frequencies of human-perceived colours to understand natural selection on snail shells may have missed a significant part of the picture. Not only may birds use both achromatic and chromatic cues to differentiate morphs, but they should also be able to perceive chromatic differences to a much finer precision than a simple trivariate yellow, pink or brown categorisation that humans are obliged to use in qualitative surveys. Of course, this does not mean that birds react to the many
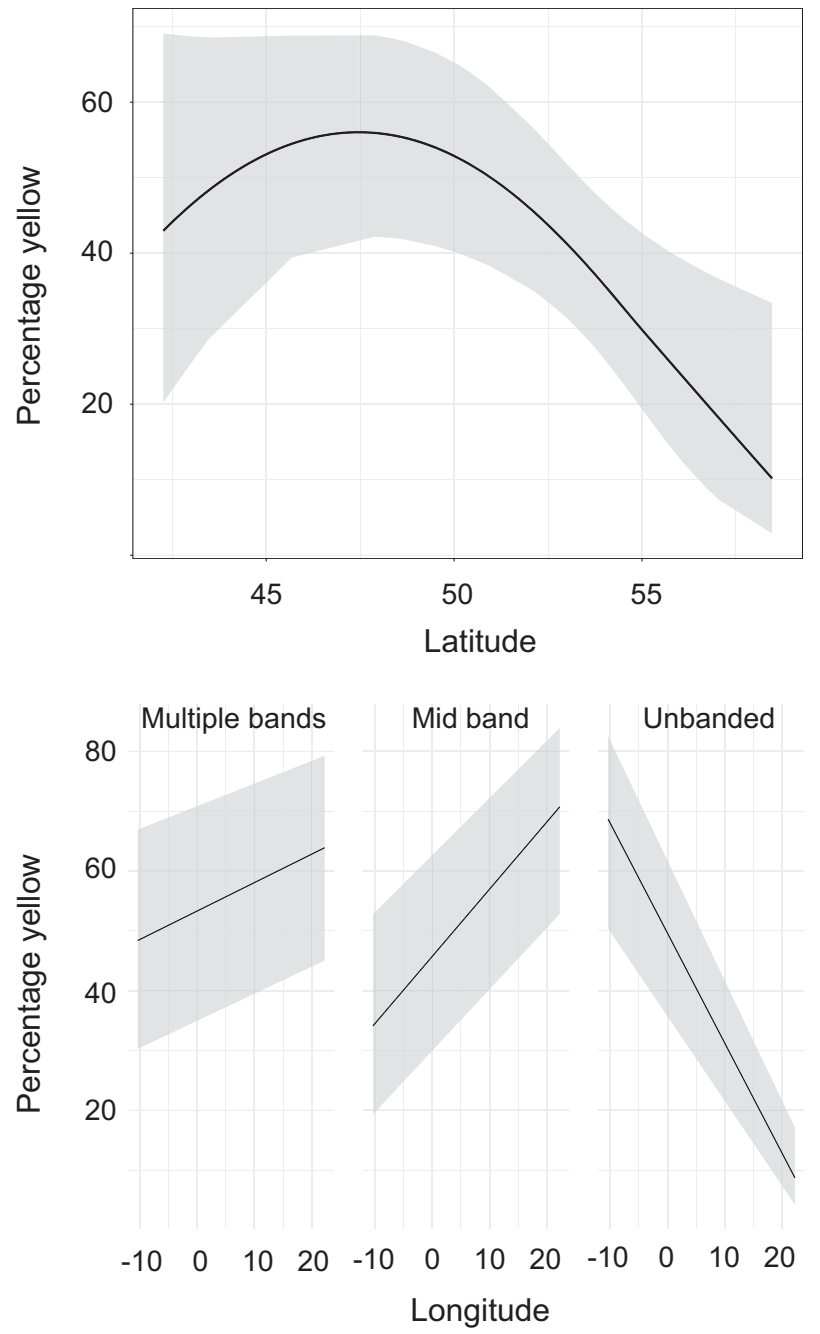

Fig. 7 Scaled effects of latitude on the proportion of yellow shells (top), and longitude on banding and proportion of yellow shells, showing $95 \%$ confidence limits

morphs equally - it is possible that they categorically perceive a continuous variable (Caves et al. 2018). Further investigations are needed, especially using a bird such as the song thrush.

The effects of geographic location and banding pattern on variation in the reflectance spectrum of snails were also examined, as perceived by an avian predator. The initial aim was to develop methods to describe variation, rather to explain it (e.g. by looking for correlations with environmental variables, putative selective agents, etc., as others have done; Silvertown et al. 2011). Generally, we found that geographic variables (latitude, longitude and region) and banding are generally associated with different frequencies of the three traditional colour morphs, with the main directional trend being that yellow snails are most common at mid-latitudes, as was found in much larger studies (Jones et al. 1977; Silvertown et al. 2011). Similarly, as previously reported Cain et al. 1960, epistasis meant that 
unbanded snails $(\mathrm{O})$ were generally more likely to be brown, and banded snails (B) were less likely to be brown. Therefore, by establishing a method for quantitatively measuring colour, and showing that a relatively small sample can be used to infer wide geographic patterns, this work provides a baseline for further studies on the polymorphism.

\section{Discrete or indiscrete?}

Laboratory crosses in the past have revealed that the variation in the Cepaea shell phenotype is predominantly controlled by a "supergene", which in a recent definition is a genetic architecture involving multiple linked functional genetic elements that allows switching between discrete, complex phenotypes maintained in a stable local polymorphism (Llaurens et al. 2017; Thompson and Jiggins 2014). This meaning fits with the traditional view - and the classical "Fordian" theory of polymorphism (Ford 1964) that the ground colour of the shell is one of three more or less discrete colour classes, either yellow, pink or brown, and indeed, is part of the reason that Cepaea snails became a well-studied system. However, while scoring the shell colour into different, discrete types is straightforward in offspring of individual crosses in the lab, the acknowledged reality is that it is sometimes difficult to classify shells consistently (e.g. see Table 1), especially when they are apparently intermediate in form.

As we have shown definitively that the colour polymorphism of Cepaea nemoralis is not discrete at a broad geographic scale (Figs. 2, 4), this finding emphasises the specific practical problem for projects collecting and using shell polymorphism data, especially those-based entirely in the field and using citizen science (e.g. Evolution Megalab; Silvertown et al. 2011). However, it also illustrates a more general problem: if we do not have a precise definition of the Cepaea phenotype/polymorphism and an understanding of the underlying genetic control, then how can we claim to understand the evolutionary and ecological factors that maintain colour variation?

Mathematical modelling is one method that can be used to explore the evolution of polymorphism, and of most relevance to this work, the circumstances that may or may not lead to discrete phenotypes. Historically, the argument of Ford was that despite the fact that supergenes may appear as Mendelian loci, they were actually rather complicated arrangements of several loci that are effectively prevented from being broken up by recombination under most normal circumstances. Thus, in both colour polymorphism in general (e.g. in side-blotched lizards; Sinervo and Lively 1996) and specifically relating to supergenes (e.g. in butterfly mimicry rings; Joron et al. 2011; Kunte et al. 2014), the distinctiveness of the morphs is a central feature of the genetic control; the genetic architecture specifically prevents phenotypes from "dissolving" into continuous trait distributions (Ford 1964).

Much of the existing research has therefore begun from the premise of understanding how evidently discrete types come about, and thus give insight into the adaptive evolution of genome structure (Cuthill et al. 2017). In simulations it has been shown that natural selection tends to favour lowered recombination when intermediate genotypes are at a disadvantage; unlinked loci modify the phenotype to adapt to local conditions (e.g. to a local Batesian model butterfly; Charlesworth and Charlesworth 1975a; Charlesworth and Charlesworth 1975b; Llaurens et al. 2017). More recently, and perhaps most directly relevant to understanding the Cepaea polymorphism, Kopp and Hermisson (2006) devised a model to investigate the evolution of a quantitative trait under frequency-dependent disruptive selection. Their finding was that over generations most of the genetic variation tends to concentrate on a small number of loci.

The historic background is perhaps part of the reason that most of the recent progress in understanding supergenes has mainly come from species or systems that show simple, wholly discrete phenotypes, for example in butterfly mimicry rings (Joron et al. 2011), or heterostylous plants (Li et al. 2016). However, in Cepaea we have shown that there are many colour morphs, such that colour variation is quantitative and due to a supergene; in other species such as the guppy Poecilia and the cichlid Labeotropheus, the inheritance of often considerable colour variation is due to several loci, some sex-linked and others not (Thompson and Jiggins 2014; Tripathi et al. 2009; Wellenreuther et al. 2014). Thus, developing theory on the impact of negative frequencydependent (apostatic) selection must be able to account for these complexities, including those where supergenes are absent and variation is quantitative, otherwise there is a risk that models will simply reaffirm what we already know.

In one recent model, it was shown that crypsis and apostatic selection together may act to maintain a large number of morphs within a population, and in another apostatic selection was shown to maintain variation between similar species (Franks and Oxford 2011; Franks and Oxford 2017). In another more recent study, a simulation was used to explore the influence of predator perspective, selection, migration, and genetic linkage on colour allele frequencies (Holmes et al. 2017). The main finding was that relative sizes of predator and prey home ranges can result in large differences in morph composition between neighbouring populations. Finally, in an empirical study, blue jays Cyanocitta cristata searched for digital moths on mixtures of dark and light patches at different scales of heterogeneity. It was found that complex backgrounds with many moth-like features elicited a slow, serial search that depended heavily on selective attention. The result was 
increased apostatic selection, producing a broad range of moth phenotypes (Bond and Kamil 2006). All of these circumstances may apply to the Cepaea colour polymorphism.

In comparison, a few more general studies on colour polymorphism, rather than on supergenes specifically, have begun to reveal the extent of phenotypic variation, and whether discrete or indiscrete. For example, reflectance spectra have been used to show that even though humans perceived the colour variation in the eggs of African cuckoo finch Anomalospiza imberbis as falling into discrete categories, the variation was actually continuous (Spottiswoode and Stevens 2010; Spottiswoode and Stevens 2011). Similarly, tawny dragon lizard Ctenophorus descresii does have discrete colour morphs, but there is still considerable variation within each morph (Teasdale et al. 2013). Further quantitative studies in other lizards in which colour polymorphism has traditionally been treated as qualitative are also increasingly showing that these colours are sometimes indiscrete (Cote et al. 2008; Paterson and Blouin-Demers 2017; Rankin et al. 2016; Vercken et al. 2008).

Overall, there is an open debate - but few empirical data - on how the relative heterogeneity of the environment/ substrate, density, distance or motion may influence the selection for crypsis or negative frequency dependence (Barnett et al. 2018; Cuthill et al. 2017). As Surmacki et al. (2013) summarised, if heterogeneous areas consist of large patches of diverse habitats then this may promote the evolution of specialist morphs through selection for crypsis, producing a few distinct or specialist morphs, each more or less well matched to the coloration of the preferred habitat type (Bond 2007; Endler 1978). If instead there is a mixture of small microhabitats, apostatic selection is more likely to result in multiple morphs that may be equally cryptic in all "grains" of the habitat. This is because in such circumstances, predators use search images of the most common morph, and this can lead to frequency-dependent selection.

\section{Supergenes return}

In contrast to a relative paucity of field data, and a relative lack of progress in establishing baseline theory, advances in DNA sequencing technology have meant that knowledge on the genetics of colour polymorphism is advancing rapidly. As hypothesised, in the still relatively few supergenes that have been fully characterised, the discrete phenotypes are maintained due to close physical proximity of the gene(s) and/or tight linkage (Gautier et al. 2018; Joron et al. 2011; Kunte et al. 2014).

In Cepaea nemoralis snails, the colour and banding elements of the supergene have been mapped (Ramos Gonzalez et al. 2018; Richards et al. 2013) but we remain ignorant of the underlying genetics and the precise nature of the selection that acts upon the polymorphism. For instance, models of supergene evolution require that intermediate phenotypes are disadvantaged - this makes sense with respect to Batesian mimics or distylous flowers - but in snails a rare intermediate might be at an advantage, due to apostatic selection. At the molecular level, one scenario is that the extreme and effectively continuous colour variation of the shells that we found is due to a corresponding high number of colour alleles within the supergene. An alternative scenario is that there are actually relatively few colour alleles, with much of the chromatic variation due to effects of other modifying loci (Charlesworth and Charlesworth 1975b). It is interesting to note that to date few studies that have explicitly investigated the genetic basis of quantitative variation at these other loci (Huber et al. 2015; Jones et al. 2012).

A further consideration is that it is of course very difficult to rule out some of the minor differences as being due to experimental error, as well as other non-genetic effects. A final issue is that while colour variation might be continuous across a grand geographic scale, if most local populations are founded by few individuals, then local variation might be discrete, which is all that matters from a selective point of view. This is more likely to be the case when both colour and banding are considered as the visible phenotype, especially since they are frequently in linkage disequilibrium (Cook 2017).

Clearly, scale is important - although we found that variation is continuous at large geographic scale, our analyses indicate that colour variation is sometimes discrete at a local level. This conclusion is dependent upon the viewer, whether human or machine, and the specific population. For example, the colour of a Beeston population was straightforward to score by eye, and this was more or less matched by the spectrophotometric/Mclust inferences (Fig. 5a, b: Supplementary Movies 3, 4). In comparison, the colour of a Bathhill population was more difficult to score by eye, and showed greater differences in Mclust classifications.

In a general sense, these results also show that while there is a clear benefit in using a spectrophotometer to objectively measure colour, this colour is from a very specific and small region of the shell. In comparison, human perception is perhaps better able to judge on the overall colour. The two methods are not necessarily measuring the same thing and so there is no expectation that the two methods should produce exactly the same outcome, even if we were to use a human model of colour vision in the analysis.

\section{Conclusions}

Overall, by establishing a method for quantitatively measuring colour, this work provides a baseline for further 
studies on the polymorphism, both from the perspective of understanding the nature of selection, and ultimately, also the genes involved. To reconcile and test competing theories with the empirical observations, a next step must be to identify the component parts and evolutionary origins of the supergene in $C$. nemoralis.

This work has shown how an avian predator might perceive colour, but not how it would categorise and react to specific elements of the chromatic variation (Caves et al. 2018). Snails may escape predation because the colour is cryptic against a background, or simply because it is different from the majority of others (apostatic selection); a further consideration is that dark shells exposed to the sun reach a higher temperature than light shells, inducing climatic selection (Jones et al. 1977; Richardson 1974). In the future, we should try to understand the spatial distribution of colour morphs, from the perspective of these three modes of selection, and random genetic drift. Only then may we begin to understand the evolutionary and ecological factors that maintain this superlative example of colour polymorphism.

\section{Data archiving}

Reflectance data, location and shell colour classifications are supplied in Supplementary Table 2.

Acknowledgements This work was supported by the University of Nottingham, with a spectrophotometer purchased on the UoN equipment fund; and the Biotechnology and Biological Sciences Research Council [grant number BB/M008770/1], via a studentship to Hannah Jackson. Thanks to both Alan Bond and Laurence Cook for helpful discussions, comments from two anonymous referees, Kaspar Delhey for discussion and assistance with the methods, Alice Maiden and Shagufta Hadife for help collecting data, and Adele Grindon and a network of helpers who originally collected many of the snails.

\section{Compliance with ethical standards}

Conflict of interest The authors declare that they have no conflict of interest.

Publisher's note: Springer Nature remains neutral with regard to jurisdictional claims in published maps and institutional affiliations.

Open Access This article is licensed under a Creative Commons Attribution 4.0 International License, which permits use, sharing, adaptation, distribution and reproduction in any medium or format, as long as you give appropriate credit to the original author(s) and the source, provide a link to the Creative Commons license, and indicate if changes were made. The images or other third party material in this article are included in the article's Creative Commons license, unless indicated otherwise in a credit line to the material. If material is not included in the article's Creative Commons license and your intended use is not permitted by statutory regulation or exceeds the permitted use, you will need to obtain permission directly from the copyright holder. To view a copy of this license, visit http://creativecommons. org/licenses/by/4.0/.

\section{References}

Barnett JB, Michalis C, Scott-Samuel NE, Cuthill IC (2018) Distancedependent defensive coloration in the poison frog Dendrobates tinctorius, Dendrobatidae. Proc Natl Acad Sci USA 115:6416-6421

Bond AB (2007) The evolution of color polymorphism: crypticity searching images, and apostatic selection. Annu Rev Ecol Evol Syst 38:489-514

Bond AB, Kamil AC (2006) Spatial heterogeneity, predator cognition, and the evolution of color polymorphism in virtual prey. Proc Natl Acad Sci USA 103:3214-3219

Cain AJ, King JMB, Sheppard PM (1960) New data on the genetics of polymorphism in the snail Cepaea nemoralis L. Genetics 45:393-411

Cain AJ, Sheppard PM (1954) Natural selection in Cepaea. Genetics 39:89-116

Cain AJ, Sheppard PM, King JMB (1968) Studies on Cepaea. I. Genetics of some morphs and varieties of Cepaea nemoralis (L). Philos Trans R Soc Lond B Biol Sci 253:383-396

Cameron RAD, Cook LM (2012) Habitat and the shell polymorphism of Cepaea nemoralis (L.): interrogating the Evolution Megalab database. J Mollusca Stud 78:179-184

Cameron RAD, Cook LM, Greenwood JJD (2013) Change and stability in a steep morph-frequency cline in the snail Cepaea nemoralis (L.) over 43 years. Biol J Linn Soc 108:473-483

Cassey P, Honza M, Grim T, Hauber ME (2008) The modelling of avian visual perception predicts behavioural rejection responses to foreign egg colours. Biol Lett 4:515-517

Caves EM, Green PA, Zipple MN, Peters S, Johnsen S, Nowicki S (2018) Categorical perception of colour signals in a songbird. Nature 560:365-367

Charlesworth D, Charlesworth B (1975a) Theoretical genetics of Batesian mimicry I. Single-locus models. J Theor Biol 55:283-303

Charlesworth D, Charlesworth B (1975b) Theoretical Genetics of Batesian Mimicry II. Evolution of supergenes. J Theor Biol 55:305-324

Cook LM (2014) Morph frequency in British Cepaea nemoralis: what has changed in half a century? J Mollusca Stud 80:43-46

Cook LM (2017) Reflections on molluscan shell polymorphisms. Biol J Linn Soc 121:717-730

Cook LM, Cowie RH, Jones JS (1999) Change in morph frequency in the snail Cepaea nemoralis on the Marlborough Downs. Heredity 82:336-342

Corl A, Bi K, Luke C, Challa AS, Stern AJ, Sinervo B et al. (2018) The genetic basis of adaptation following plastic changes in coloration in a novel environment. Curr Biol 28:2970-2977. e2977

Cote J, Le Galliard JF, Rossi JM, Fitze PS (2008) Environmentally induced changes in carotenoid-based coloration of female lizards: a comment on Vercken et al. J Evol Biol 21:1165-1172

Cuthill IC (2006) Color perception. In: Hill GE, McGraw KJ (eds) Bird coloration. Harvard University Press, Cambridge (MA), p 3-40. Vol. I

Cuthill IC, Allen WL, Arbuckle K, Caspers B, Chaplin G, Hauber ME et al. (2017) The biology of color. Science 357:eaan0221

Dale J, Dey CJ, Delhey K, Kempenaers B, Valcu M (2015) The effects of life history and sexual selection on male and female plumage colouration. Nature 527:367-370

Davison A, Clarke B (2000) History or current selection? A molecular analysis of 'area effects' in the land snail Cepaea nemoralis. Proc R Soc Lond B Biol Sci 267:1399-1405

Delhey K, Delhey V, Kempenaers B, Peters A (2015) A practical framework to analyze variation in animal colors using visual models. Behav Ecol 26:367-375 
Delhey K, Szecsenyi B, Nakagawa S, Peters A (2017) Conspicuous plumage colours are highly variable. Proc R Soc Lond B Biol Sci 284:20162593

Eacock A, Rowland HM, Edmonds N, Saccheri IJ (2017) Colour change of twig-mimicking peppered moth larvae is a continuous reaction norm that increases camouflage against avian predators. Peerj 5:e3999

Endler J (1978) A predator's view of animal color patterns. In: Hecht MK, Steere WC, Wallace B (eds) Evolutionary biology. Plenum Press, New York, NY, p 319-364. Vol. 11

Endler JA (1990) On the measurement and classification of color in studies of animal color patterns. Biol J Linn Soc 41:315-352

Ford EB (1964) Ecological Genetics. Methuen, London

Franks DW, Oxford GS (2011) The interrelationship between crypsis and colour polymorphism. Ecol Lett 14:295-300

Franks DW, Oxford GS (2017) The co-evolution of anti-predator polymorphisms in sympatric populations. Biol $\mathrm{J}$ Linn Soc 122:729-737

Gautier M, Yamaguchi J, Foucaud J, Loiseau A, Ausset A, Facon B et al. (2018) The genomic basis of color pattern polymorphism in the Harlequin Ladybird. Curr Biol 28:3296-3302.e3297

Grindon AJ, Davison A (2013) Irish Cepaea nemoralis land snails have a cryptic Franco-Iberian origin that is most easily explained by the movements of Mesolithic humans. PLoS ONE 8:e65792

Hart NS (2001) Variations in cone photoreceptor abundance and the visual ecology of birds. J Comp Physiol A, Sens Neural Behav Physiol 187:685-697

Hart NS, Partridge JC, Cuthill IC, Bennett AT (2000) Visual pigments, oil droplets, ocular media and cone photoreceptor distribution in two species of passerine bird: the blue tit (Parus caeruleus L.) and the blackbird (Turdus merula L.). J Comp Physiol A $186: 375-387$

Hoekstra HE (2006) Genetics, development and evolution of adaptive pigmentation in vertebrates. Heredity 97:222-234

Holmes IA, Grundler MR, Rabosky ARD (2017) Predator perspective drives geographic variation in frequency-dependent polymorphism. Am Nat 190:E78-E93

Holveck MJ, Gregoire A, Guerreiro R, Staszewski V, Boulinier T, Gomez D et al. (2017) Kittiwake eggs viewed by conspecifics and predators: implications for colour signal evolution. Biol J Linn Soc 122:301-312

Huber B, Whibley A, Poul YL, Navarro N, Martin A, Baxter S et al. (2015) Conservatism and novelty in the genetic architecture of adaptation in Heliconius butterflies. Heredity 114:515

Hugall AF, Stuart-Fox D (2012) Accelerated speciation in colourpolymorphic birds. Nature 485:631-634

Jones JS, Leith BH, Rawlings P (1977) Polymorphism in Cepaea: a problem with too many solutions? Annu Rev Ecol Syst 8:109-143

Jones RT, Salazar PA, ffrench-Constant RH, Jiggins CD, Joron M (2012) Evolution of a mimicry supergene from a multilocus architecture. Proc Biol Sci 279:316-325

Joron M, Frezal L, Jones RT, Chamberlain NL, Lee SF, Haag CR et al. (2011) Chromosomal rearrangements maintain a polymorphic supergene controlling butterfly mimicry. Nature 477:203-206

Kang C, Stevens M, Moon JY, Lee SI, Jablonski PG (2015) Camouflage through behavior in moths: the role of background matching and disruptive coloration. Behav Ecol 26:45-54

Kemp DJ, Herberstein ME, Fleishman LJ, Endler JA, Bennett ATD, Dyer AG et al. (2015) An integrative framework for the appraisal of coloration in nature. Am Nat 185:705-724

Kerkvliet J, de Boer T, Schilthuizen M, Kraaijeveld K (2017) Candidate genes for shell colour polymorphism in Cepaea nemoralis. Peerj 5:e3715
Kopp M, Hermisson J (2006) The evolution of genetic architecture under frequency-dependent disruptive selection. Evolution 60:1537-1550

Kunte K, Zhang W, Tenger-Trolander A, Palmer DH, Martin A, Reed $\mathrm{RD}$ et al. (2014) Doublesex is a mimicry supergene. Nature 507:229-232

Li JH, Cocker JM, Wright J, Webster MA, McMullan M, Dyer S et al. (2016) Genetic architecture and evolution of the S locus supergene in Primula vulgaris. Nat Plants 2:16188

Llaurens V, Whibley A, Joron M (2017) Genetic architecture and balancing selection: the life and death of differentiated variants. Mol Ecol 26:2430-2448

Maia R, Eliason CM, Bitton PP, Doucet SM, Shawkey MD (2013) pavo: an $\mathrm{R}$ package for the analysis, visualization and organization of spectral data. Methods Ecol Evol 4:906-913

Maia R, White TE (2018) Comparing colors using visual models. Behav Ecol 29:649-659

Mann K, Jackson DJ (2014) Characterization of the pigmented shellforming proteome of the common grove snail Cepaea nemoralis. BMC Genom 15:249

McKinnon JS, Pierotti MER (2010) Colour polymorphism and correlated characters: genetic mechanisms and evolution. Mol Ecol 19:5101-5125

McLean CA, Stuart-Fox D (2014) Geographic variation in animal colour polymorphisms and its role in speciation. Biol Rev $89: 860-873$

Montgomerie R (2006) Analysing Colors. In: Hill GE, McGraw KJ (eds) Bird Coloration. Harvard University Press, Cambridge (MA), p 90-147. Vol. I

Olsson P, Lind O, Kelber A (2018) Chromatic and achromatic vision: parameter choice and limitations for reliable model predictions. Behav Ecol 29:273-282

Osorio D, Miklosi A, Gonda Z (1999) Visual ecology and perception of coloration patterns by domestic chicks. Evol Ecol 13:673-689

Osorio D, Vorobyev M (2005) Photoreceptor spectral sensitivities in terrestrial animals: adaptations for luminance and colour vision. Proc R Soc Biol Sci Ser B 272:1745-1752

Ożgo M, Liew TS, Webster NB, Schilthuizen M (2017) Inferring microevolution from museum collections and resampling: lessons learned from Cepaea. Peerj 5:e3938

Ożgo M, Schilthuizen M (2012) Evolutionary change in Cepaea nemoralis shell colour over 43 years. Glob Change Biol 18:74-81

Paterson JE, Blouin-Demers G (2017) Distinguishing discrete polymorphism from continuous variation in throat colour of tree lizards, Urosaurus ornatus. Biol J Linn Soc 121:72-81

Pike TW (2018) Quantifying camouflage and conspicuousness using visual salience. Methods Ecol Evol 9:1883-1895

Ramos Gonzalez D, Caro Aramendia A, Davison A (2018) Recombination within the Cepaea nemoralis supergene is confounded by incomplete penetrance and epistasis. Heredity (in press)

Rankin KJ, McLean CA, Kemp DJ, Stuart-Fox D (2016) The genetic basis of discrete and quantitative colour variation in the polymorphic lizard, Ctenophorus decresii. BMC Evol Biol 16:179

Richards PM, Liu MM, Lowe N, Davey JW, Blaxter ML, Davison A (2013) RAD-Seq derived markers flank the shell colour and banding loci of the Cepaea nemoralis supergene. Mol Ecol 22:3077-3089

Richardson AM (1974) Differential climatic selection in naturalpopulation of land snail Cepaea nemoralis. Nature 247:572-573

San-Jose LM, Roulin A (2017) Genomics of coloration in natural animal populations. Philos Trans R Soc Lond B Biol Sci 372:20160337

Schilthuizen M (2013) Rapid, habitat-related evolution of land snail colour morphs on reclaimed land. Heredity 110:247-252 
Scrucca L, Fop M, Murphy TB, Raftery AE (2016) Mclust 5: clustering, classification and density estimation using Gaussian finite mixture models. R J 8:205-233

Silvertown J, Cook L, Cameron R, Dodd M, McConway K, Worthington $\mathrm{J}$ et al. (2011) Citizen science reveals unexpected continental scale evolutionary change in a model organism. PLOS ONE 6:e18927

Sinervo B, Lively CM (1996) The rock-paper-scissors game and the evolution of alternative male strategies. Nature 380:240

Spottiswoode CN, Stevens M (2010) Visual modeling shows that avian host parents use multiple visual cues in rejecting parasitic eggs. Proc Natl Acad Sci USA 107:8672-8676

Spottiswoode CN, Stevens M (2011) How to evade a coevolving brood parasite: egg discrimination versus egg variability as host defences. Proc R Soc Biol Sci Ser B 278:3566-3573

Staples-Browne R (1908) On the inheritance of colour in domestic pigeons, with special reference to reversion. Proc Zool Soc Lond 78:67-104

Surmacki A, Ozarowska-Nowicka A, Rosin ZM (2013) Color polymorphism in a land snail Cepaea nemoralis (Pulmonata: Helicidae) as viewed by potential avian predators. Naturwissenschaften 100:533-540

Taylor CH, Reader T, Gilbert F (2016) Hoverflies are imperfect mimics of wasp colouration. Evol Ecol 30:567-581

Teasdale LC, Stevens M, Stuart-Fox D (2013) Discrete colour polymorphism in the tawny dragon lizard (Ctenophorus decresii) and differences in signal conspicuousness among morphs. J Evol Biol 26:1035-1046

Thompson MJ, Jiggins CD (2014) Supergenes and their role in evolution. Heredity 113:1-8

Tripathi N, Hoffmann M, Willing EM, Lanz C, Weigel D, Dreyer C (2009) Genetic linkage map of the guppy, Poecilia reticulata, and quantitative trait loci analysis of male size and colour variation. Proc R Soc Biol Sci Ser B 276:2195-2208

Vercken E, Sinervo B, Clobert J (2008) Colour variation in female common lizards: why we should speak of morphs, a reply to Cote et al. J Evol Biol 21:1160-1164

Vorobyev M, Osorio D (1998) Receptor noise as a determinant of colour thresholds. Proc R Soc Lond B Biol Sci 265:351-358

Vorobyev M, Osorio D, Bennett ATD, Marshall NJ, Cuthill IC (1998) Tetrachromacy, oil droplets and bird plumage colours. J Comp Physiol A 183:621-633

Wellenreuther M, Svensson EI, Hansson B (2014) Sexual selection and genetic colour polymorphisms in animals. Mol Ecol 23:5398-5414

Wheldale M (1907) The inheritance of flower colour in Antirrhinum majus. Proc R Soc Biol Sci Ser B 79:288-305

White TE, Kemp DJ (2016) Color polymorphic lures target different visual channels in prey. Evolution 70:1398-1408

Williams ST (2017) Molluscan shell colour. Biol Rev 92:1039-1058

Zuur A, Ieno EN, Walker N, Saveliev AA, Smith GM (2009) Mixed effects models and extensions in ecology with R. Springer-Verlag, New York, NY 